\title{
BE-SMART (Basal Early Strategies to Maximize HbA1c Reduction with Oral Therapy): Expert Opinion
}

\author{
Sarita Bajaj · A. K. Das - Sanjay Kalra - Rakesh Sahay • Banshi Saboo - Sambit Das • M. Shunmugavelu • \\ Jubbin Jacob • Gagan Priya • Deepak Khandelwal • Deep Dutta • Manoj Chawla • Vineet Surana • \\ Mangesh Tiwaskar • Ameya Joshi • Pradip Krishna Shrestha • Jyoti Bhattarai • Bishwajit Bhowmik • \\ Tint Swe Latt • Than Than Aye - G. Vijayakumar • Manash Baruah • Fatema Jawad • A. G. Unnikrishnan • \\ Subhankar Chowdhury · Md. Faruqe Pathan · Noel Somasundaram • Manilka Sumanathilaka • Abbas Raza • \\ Silver K. Bahendeka · Ankia Coetzee · Sundeep Ruder · Kaushik Ramaiya • Roberta Lamptey • Charlotte Bavuma • \\ Khalid Shaikh • Andrew Uloko • Sandeep Chaudhary • Abdurezak Ahmed Abdela • Zhanay Akanov • \\ Joel Rodrìguez-Saldaña $\cdot$ Raquel Faradji $\cdot$ Armindo Tiago $\cdot$ Ahmed Reja $\cdot$ Leszek Czupryniak
}

Received: March 19, 2019 / Published online: May 17, 2019

(C) The Author(s) 2019

\section{ABSTRACT}

The past three decades have seen a quadruple rise in the number of people affected by diabetes mellitus worldwide, with the disease being the ninth major cause of mortality. Type 2 diabetes mellitus (T2DM) often remains undiagnosed for

Enhanced Digital Features To view enhanced digital features for this article go to https://doi.org/10.6084/ m9.figshare.8035433.

S. Bajaj

Department of Medicine, MLN Medical College,

Allahabad, India

A. K. Das

Department of Medicine, JIPMER, Puducherry, India

S. Kalra $(\bowtie)$

Department of Diabetes and Endocrinology, Bharti

Hospital, Karnal, India

e-mail: brideknl@gmail.com

R. Sahay

Department of Endocrinology, Osmania Medical

College and Hospital, Hyderabad, India

B. Saboo

Diacare-Diabetes Care and Hormone Clinic,

Ahmedabad, India

S. Das

Department of Endocrinology, Apollo Hospitals, Bhubaneswar, India several years due to its asymptomatic nature during the initial stages. In India, 70\% of diagnosed diabetes cases remain uncontrolled. Current guidelines endorse the initiation of insulin early in the course of the disease, specifically in patients with $\mathrm{HbA1c}>10 \%$, as the use of oral agents alone is unlikely to achieve glycemic targets. Early insulin initiation and optimization of glycemic control using insulin titration algorithms and patient empowerment can facilitate the effective management of uncontrolled diabetes. Early glucose control has sustained

M. Shunmugavelu

Trichy Diabetes Speciality Centre (P) Ltd., Trichy, India

\section{J. Jacob}

Endocrine and Diabetes Unit, Department of Medicine, Christian Medical College and Hospital, Ludhiana, India

G. Priya

Fortis Hospital, Mohali, India

\section{Khandelwal}

Department of Endocrinology, Maharaja Agrasen Hospital, Delhi, India

\section{Dutta}

Department of Endocrinology, Diabetology and Metabolic Disorders, Venkateshwar Hospital, New Delhi, India 
benefits in people with diabetes. However, insulin initiation, dose adjustment, and the need to repeatedly assess blood glucose levels are often perplexing for both physicians and patients, and there are misconceptions and concerns regarding its use. Hence, an early transition to insulin and ideal intensification of treatment may aid in delaying the onset of diabetes complications. This opinion statement was formulated by an expert panel on the basis of existing guidelines, clinical experience, and economic and cultural contexts. The statement stresses the timely and appropriate use of basal insulin in T2DM. It focuses on the seven vital Ts-treatment initiation, timing of administration, transportation and storage, technique of administration, targets for titration, tablets, and tools for monitoring.

Funding: Sanofi.

Keywords: Basal insulin; Degludec; Detemir; Glargine; Hypoglycemia; Titration; Type 2 diabetes mellitus

\section{INTRODUCTION}

In the past three decades, there has been a quadruple rise in the number of people affected by diabetes mellitus worldwide, such that the

M. Chawla

Lina Diabetes Care and Mumbai Diabetes Research

Centre, Mumbai, India

V. Surana

Manipal Hospitals, New Delhi, India

M. Tiwaskar

Shilpa Medical Research Centre, Mumbai, India

A. Joshi

Bhaktivedanta Hospital and Research Institute,

Thane, India

P. K. Shrestha

Nidan Hospital Pvt. Ltd., Patan, Nepal

J. Bhattarai

Metro Kathmandu Hospital, Kathmandu, Nepal

B. Bhowmik

Centre for Global Health Research, Diabetic

Association of Bangladesh, Dhaka, Bangladesh disease is now the ninth major cause of mortality [1]. In 1980, the estimated number of persons with diabetes was 108 million; by 2014, this figure had escalated to 422 million. The age-standardized global prevalence of diabetes has almost doubled, increasing from $4.7 \%$ to $8.5 \%$ in the adult population, reflecting a rise in associated risk factors such as obesity. In 2012, diabetes was the direct cause of 1.5 million deaths; additionally, by increasing the risks of cardiovascular and other diseases, higher-thanoptimal blood glucose resulted in another 2.2 million deaths. Of these 3.7 million deaths linked to high glocuse levels, $43 \%$ occurred in people under 70 years of age [2].

The recent International Diabetes Federation (IDF) atlas predicted that the number of people with diabetes will rise to 693 million by 2045 . In Africa, the number of people with diabetes is expected to rise by $162.5 \%$ by 2045 . Southeast Asia is home to $19.3 \%$ (82 million adults) of the global diabetic population, and $84.5 \%$ of all undiagnosed cases of diabetes are in low- and middle-income countries. Nearly $45.8 \%$ of adults with diabetes in Southeast Asia are undiagnosed, while over two-thirds $(69.2 \%)$ of adults with diabetes in the African region are undiagnosed [3].

Type 2 diabetes mellitus (T2DM) often remains undiagnosed for many years, owing to its asymptomatic nature during the initial

T. S. Latt

University of Medicine 2, Yangon, Myanmar

T. T. Aye

University of Medicine 2, Myanmar Society of Endocrinology and Metabolism (MSEM), Yangon, Myanmar

G. Vijayakumar

Apollo Specialty Hospital and Diabetes Medicare

Centre, Chennai, India

M. Baruah

Excel Care Hospitals, Guwahati, India

F. Jawad

Journal of Pakistan Medical Association, Karachi, Pakistan

A. G. Unnikrishnan

Chellaram Diabetes Hospital, Pune, India 
stages, during which the body is exposed to hyperglycemia, bringing about irreversible organ damage [4]. In India, 70\% of diagnosed diabetes cases remain uncontrolled [5]. Oncedaily dosing of basal insulin with continued use of one or more oral antidiabetic drugs (OADs) has proven to be an effective and safe glucoselowering treatment in most insulin-naive patients. It has various advantages-only one insulin injection may be required each day, with no need to mix different types of insulin, and titration can be accomplished in a slow and safe manner. Moreover, this combination therapy requires a lower total dose of insulin. This combination approach was popularized by the BIDS regimen, which combines a basal insulin (BI) with a sulfonylurea (DS) [6].

The ORIGIN trial showed that therapy with basal insulin glargine had a neutral effect on cardiovascular outcomes and cancers while permitting near-normal glycemic control and slowing the progression of dysglycemia [7]. However, early glucose control has shown sustained benefits in people with diabetes; it reduced the risks of macro- and microvascular complications [8] and even lowered the risk of cardiovascular complications in other trials such as the Diabetes Control and Complications Trial (DCCT) and the UK Prospective Diabetes Study (UKPDS) [9, 10]. Studies such as GOAL assessed the clinical and nonclinical predictive

S. Chowdhury

Department of Endocrinology, IPGME\&R and SSKM Hospital, Kolkata, India

Md. F. Pathan

Department of Endocrinology, BIRDEM General

Hospital, Dhaka, Bangladesh

N. Somasundaram

Diabetes and Endocrine Unit, National Hospital of Sri Lanka, Colombo, Sri Lanka

M. Sumanathilaka

National Hospital of Sri Lanka, Sri Lanka College of Endocrinologists, Colombo, Sri Lanka

A. Raza

Shaukat Khanum Memorial Cancer Hospital and Research Center, Lahore, Pakistan

S. K. Bahendeka

Mother Kevin Postgraduate Medical School, Martyrs

University, St. Francis Hospital, Kampala, Uganda factors for achieving the glycemic HbA1c goal as targeted by the treating physician in adults with type 2 diabetes requiring insulin initiation, titration, and/or intensification [11].

Current guidelines endorse the initiation of insulin early in the course of the disease, particularly in patients with $\mathrm{HbA1c}>10 \%$, as the use of oral agents alone is unlikely to achieve glycemic targets in patients with uncontrolled diabetes. Early insulin initiation and optimization of glycemic control using insulin titration algorithms and patient empowerment can help to effectively manage uncontrolled diabetes. Self-monitoring of blood glucose (SMBG), education about insulin, and the ability of those with diabetes to detect and manage hypoglycemia can significantly facilitate this process $[12,13]$.

Even though treatment with insulin is acknowledged to be the most effective treatment for T2DM, it is considered to be challenging and time-consuming for both the patient and the healthcare provider [14]. Insulin initiation, insulin dose adjustment, and the need for repeated assessment of blood glucose levels are often perplexing for physicians and patients owing to misconceptions and concerns regarding its use [15]. Clinical inertia or therapeutic inertia, defined as a recognition of the problem but a failure to act, plays a role in delayed insulin initiation and optimization and

\section{A. Coetzee}

Division of Endocrinology, Department of Medicine, Stellenbosch University and Tygerberg Hospital, Society for Endocrinology, Diabetes and Metabolism, Cape Town, South Africa

\section{S. Ruder}

Life Fourways Hospital, University of the

Witwatersrand, Cape Town, South Africa

\section{K. Ramaiya}

Shree Hindu Mandal Hospital, Dar e Salaam, Tanzania

R. Lamptey

Korle Bu Teaching Hospital, University of Ghana School of Medicine and Dentistry, Accra, Ghana

C. Bavuma

College of Medicine and Health Science, University of Rwanda, Kigali, Rwanda 
thus poor glycemic control. It can be present at the patient, physician, and system levels. This therapeutic inertia may be initiation inertia (delayed initiation of insulin), titration inertia (lack of dose adjustment), intensification inertia (delayed intensification), or all three together. Reasons for this inertia may include misconceptions surrounding insulin therapy, a lack of motivation, and poor communication between patients and healthcare providers (HCPs). Apart from these, a fear of weight gain, hypoglycemia, and increasingly complex treatment regimens may also contribute to therapeutic inertia, thereby leading to poor glycemic control. Early transition to insulin and ideal intensification of treatment might aid in delaying the onset of diabetes complications. Physicians managing diabetes must aim to increase acceptance, persistence, and adherence to insulin therapy by focusing on the safety, simplicity, and convenience of the therapy $[14,16,17]$.

The members of the expert panel have formulated this opinion statement on the basis of current disease concepts among physicians, clinical experience, available research evidence, and economic and logistic constraints that are prevalent in India and other countries whose members were involved in this panel. This article is based on previously conducted studies

K. Shaikh

Department of Diabetes, Faculty of Internal

Medicine, Royal Oman Police Hospital, Muscat,

Oman

A. Uloko

College of Health Sciences, Bayero University, Kano,

Nigeria

S. Chaudhary

NMC Speciality Hospital, Dubai, UAE

A. A. Abdela

Department of Internal Medicine, School of Medicine, CHS, Addis Ababa University, Addis

Ababa, Ethiopia

Z. Akanov

Kazakh Society for Study of Diabetes, Almaty, Kazakhstan

J. Rodrìguez-Saldaña

Multidisciplinary Diabetes Center of Mexico,

Mexico City, Mexico and does not involve any new study on human or animal subjects performed by any of the authors.

\section{BE-SMART EXPERT OPINION}

This expert opinion is focused on the timely and appropriate use of basal insulin in T2DM treatment [early basal insulin initiation and optimization, with a focus on the role of basal insulin supported oral therapy (BOT)]. It focuses on the seven vital Ts-treatment initiation, timing of administration, transportation and storage, technique of administration, targets for titration, tablets, and tools for monitoring. The 7-T concept can be a useful reckoner to help physicians improve their understanding and optimize the use of basal insulin early in diabetes treatment along with oral antiglycemic agents, thereby improving outcomes.

\section{Treatment Initiation}

- Timely insulin initiation leads to a long-term reduction in complications and improved outcomes. Clinical evidence from landmark trials such as the Diabetes Control and Complications Trial/Epidemiology of

R. Faradji

Clinica EnDi, RENACED Diabetes Tipo 1, Escuela de Medicina, TEC-ABC, Centro Médico ABC, Sociedad Mexicana de Nutrición y Endocrinología, Mexico City, Mexico

A. Tiago

Mozambican Diabetic Association, Maputo Central Hospital, Maputo, Mozambique

A. Reja

Department of Internal Medicine, Addis Ababa University, Addis Ababa, Ethiopia

L. Czupryniak

Department of Diabetology and Internal Medicine, Central University Hospital, Warsaw Medical University, Warsaw, Poland 
Diabetes Intervention and Complications Study (DCCT/EDIC) and the United Kingdom Prospective Diabetes Study (UKPDS) shows that early glucose control reduces the risk of both macro- and microvascular complications $[8,18]$. Studies have shown that targeting postprandial glucose (PPG) can help minimize cardiovascular risk $[19,20]$.

- "Metabolic karma" is a term that can effectively explain glycemic legacy in diabetes. It helps us to understand the advantages of achieving tight glycemic and metabolic control in persons with diabetes using appropriately individualized patient-centric therapy [21].

- Early insulin initiation can help overcome the glucotoxic effects of hyperglycemia and hence facilitate " $\beta$-cell rest" to preserve $\beta$-cell mass and function, while also improving insulin sensitivity [22].

- Basal insulin is a convenient and effective option for insulin initiation in the majority of patients if it does not impact post-meal hyperglycemia significantly. Basal insulin should be initiated in a timely manner, preferably within 3-6 months of inadequate control, with the optimal use of 1,2 , or 3 oral glucose-lowering agents (GLA) [12].

- Basal insulin may be initiated at the diagnosis of diabetes if catabolic symptoms are present and/or glycated hemoglobin (HbA1c) is $>10 \%$ [13].

- The basal-only regime is the most convenient initial insulin regimen, beginning at $10 \mathrm{U} /$ day or $0.1-0.2 \mathrm{U} / \mathrm{kg} /$ day, depending on the degree of hyperglycemia [12].

- In diabetes management, it is crucial that patients are involved in their treatment process. There is a need for open doctor-patient communication to achieve good glycemic control, reduce complications, and improve quality of life. Training of healthcare professionals, persons living with diabetes, and other caregivers as well as teamwork among all stakeholders are crucial to achieving optimal basal insulin use $[23,24]$.

\section{Timing of Administration}

- Basal insulin should be injected at the appropriate time (usually bedtime), in line with the prescribing information.

- Basal insulin may, under some circumstances (e.g., administration by caregivers and nursing home residents), be administered in the morning or afternoon as well, preferably at the same time daily.

- Basal insulin analogues provide the advantage of flexibility of timing, making it simple and less intrusive. They involve only one injection per day and do not require adherence to inflexible meal patterns, quantity, and composition [25].

- Neutral Protamine Hagedorn (NPH) Insulin: With NPH insulin, the preferred injection time is bedtime [26].

- First-Generation Basal Insulin Analogues (Gla-100 and Insulin Detemir): Both of the first-generation basal insulin analogues are also best administered at bedtime. Insulin glargine can be administered anytime each day, irrespective of fasting plasma glucose (FPG) levels $[25,27,28]$.

- Second-Generation Basal Insulin Analogues (Insulin Degludec and Gla-300): These offer more flexibility in the timing of injection and can be administered at any time in the day, but they have to be administered at the same time each day [29].

- Upon realizing that a dose of basal insulin has been missed, the situation can be redressed by immediately administering the dose while ensuring that there is a gap of at least an $8 \mathrm{~h}$ between injections. Once this dose has been taken, the patient can return to their regular dosing schedule.

- In fasting and special populations, the schedule for basal insulin and GLA administration shown in Table 1 should be followed.

In order to prevent episodes of hypoglycemia during fasts, such as during Ramadan, patients treated with insulin and insulin secretagogues should measure glucose before, during, and after fasting (2-4 times daily). A reduction in 
Table 1 Choice of basal insulin and GLAs in special populations

\begin{tabular}{|c|c|c|c|c|}
\hline Population & $\begin{array}{l}\text { Special } \\
\text { concern }\end{array}$ & Choice of BI & Titration & Additional GLAs \\
\hline $\begin{array}{l}\text { Fasting/ } \\
\text { Ramadan }\end{array}$ & Hypoglycemia & $\begin{array}{l}\text { Gla-100/Gla-300/ } \\
\text { degludec }\end{array}$ & Slow & $\begin{array}{l}\text { DPP4i/TZD/glipizide/ } \\
\text { repaglinide }\end{array}$ \\
\hline Pregnancy & Safety & NPH/Detemir/Glargine & $\begin{array}{l}\text { Early titration until } \\
\text { target }\end{array}$ & Metformin \\
\hline Elderly & Hypoglycemia & $\begin{array}{l}\text { Gla-100/Gla-300/ } \\
\text { degludec }\end{array}$ & Slow/weekly & DPP4i/metformin/SU \\
\hline
\end{tabular}

$B I$ basal insulin, DPP4i dipeptidyl peptidase-4 inhibitor, $N P H$ neutral protamine Hagedorn, $G L A$ oral glucose-lowering agents, $T Z D$ thiazolidinediones, $S U$ sulfonylureas

the dose of insulin secretagogues should be considered [30].

\section{Transportation and Storage}

Transport: The cold chain should be maintained during the transportation of the vials or cartridges of insulin [31].

Storage: Insulin vials, cartridges, or pens may be kept at room temperature, i.e., at $59-86^{\circ} \mathrm{F}$ $\left(15-30^{\circ} \mathrm{C}\right)$, for 28 days or about 1 month. Insulin detemir can be stored at room temperature for up to 42 days. Insulin degludec may be kept at room temperature for 2 months. Exposure to extremes of temperature can lead to a loss of insulin effectiveness and a deterioration in glycemic control. In settings where the temperatures can be above $30^{\circ} \mathrm{C}$ or below $2{ }^{\circ} \mathrm{C}$, it is not advisable to leave the vials at room temperature, and appropriate steps for storing them at an optimum temperature must be taken [32].

\section{Technique of Administration}

Insulin Injection Technique: Basal insulin should be injected into the subcutaneous space. If injected into intramuscular space, it may inadvertently behave like rapid-acting insulin. Studies with insulin showed an increased rate of absorption with intramuscular injection, and this is thought to increase the risk and severity of hypoglycemia [33].

\section{Injection Devices:}

- Syringes and vials: Disposable plastic insulin syringes are the most widely used devices for insulin injection. Insulin syringes are available with 0.3-, 0.5-, 1-, and 2-ml capacities. Needle length and thickness have been reduced to minimize the pain during the injection and to prevent inadvertent intramuscular administration of insulin.

Pinching may be necessary for some individuals with thin skin when using the $6-\mathrm{mm}$ or larger needles. A 4-mm needle is currently available for pens and a 6-mm needle is available for syringes. This means that there are options suitable for everyone, without the need for pinching. - Pen needles: Pen needles are available in different lengths: 4, 5, 6, 8, and $12.7 \mathrm{~mm}$. Shorter and thinner needles cause less pain; less penetration force can be applied with thinner needles.

Needle Reuse: Ideally, disposable syringes and pen needles should be used only once, as reuse compromises sterility. Hence, a new sterile syringe and needle for every injection is advised. However, despite reuse not being recommended, the practice is common. In such cases, reuse should be restricted to a maximum of 5 times, or fewer if the needle causes pain. Using short- and narrow-gauge $(4-5 \mathrm{~mm} \times 32 \mathrm{G})$ insulin pen needles reduces pain [34].

Site of Injection: The injection site should be inspected by a physician, especially if 
lipohypertrophy is already present or suspected [26]. When shifting the injection site from the habitual lipohypertrophy site to normal subcutaneous tissue [35], insulin dosing may be reduced by $10-20 \%$. The abdomen is the preferred site for soluble human insulin because absorption occurs the most rapidly there. In the case of NPH insulin, the thighs and buttocks are the preferred injection sites [26]. Differences in the rates of absorption at various body sites are negligible with the newer insulin analogues.

Injection-Site Rotation: In order to avoid bumps and scar tissue on the skin, the insulin injection site should be rotated. A systematic approach to injection-site rotation needs to be adopted [34].

The 2017 Indian recommendations for best practice in insulin injection are shown in Table 2 [35].

It is important to appropriately match delivery device to insulin preparation (e.g., pen and cartridge as well as vial and syringe of correct strength). All stakeholders should be educated about different types of basal insulins, including biosimilar insulins, in order to avoid inappropriate use. As far as possible, prescription sanctity should be maintained [35].

\section{Targets for Titration}

- Titration of the insulin dose is recommended using a treat-to-target approach, wherein the dose can be uptitrated to reach a predefined therapeutic goal in terms of FPG level and HbA1c [36].

- The initial basal insulin dose may be started at $10 \mathrm{U} /$ day or $0.1-0.2 \mathrm{U} / \mathrm{kg} /$ day, depending on the degree of hyperglycemia [12]. Starting with a higher dose may be required in persons with a high body mass index, high HbA1c, and longer duration of diabetes or signs of insulin resistance, such as acanthosis nigricans and/or a dorsocervical fat pad.

- The recommended treat-to-target algorithm for the initiation and titration of basal insulin in basal insulin supported by oral GLA therapy is elaborated in Fig. 1.

- While glycemic targets should be individualized, a FPG level of $100-130 \mathrm{mg} / \mathrm{dL}$
Table 2 Recommendations for insulin injection [35]

\begin{tabular}{|c|c|c|}
\hline Pre-injection & During injection & Post-injection \\
\hline $\begin{array}{l}\text { Convey the } \\
\text { benefits of } \\
\text { insulin in a } \\
\text { positive manner }\end{array}$ & $\begin{array}{l}\text { Do not inject on a } \\
\text { tight, blanched, } \\
\text { or painful skin } \\
\text { fold or bruised } \\
\text { or traumatic } \\
\text { sites }\end{array}$ & $\begin{array}{l}\text { Release skin fold, } \\
\text { if raised, slowly } \\
\text { after } \\
\text { withdrawing } \\
\text { the needle }\end{array}$ \\
\hline $\begin{array}{l}\text { Selection of } \\
\text { appropriate } \\
\text { insulin site, } \\
\text { device, needle } \\
\text { gauge, and } \\
\text { length }\end{array}$ & $\begin{array}{l}\text { Allow topical } \\
\text { alcohol to } \\
\text { evaporate }\end{array}$ & $\begin{array}{l}\text { Follow correct } \\
\text { site rotation } \\
\text { policy }\end{array}$ \\
\hline $\begin{array}{l}\text { Use a new needle } \\
\text { for each } \\
\text { injection }\end{array}$ & $\begin{array}{l}\text { Avoid injecting at } \\
\text { hair roots }\end{array}$ & \\
\hline $\begin{array}{l}\text { Use concentrated } \\
\text { insulin if the } \\
\text { dose } \\
\text { requirement is } \\
\text { high }\end{array}$ & $\begin{array}{l}\text { Penetrate the skin } \\
\text { quickly }\end{array}$ & \\
\hline $\begin{array}{l}\text { Use neutral pH } \\
\text { insulin if pain } \\
\text { occurs with } \\
\text { acidic pH } \\
\text { insulin }\end{array}$ & $\begin{array}{l}\text { Do not move the } \\
\text { needle } \\
\text { immediately } \\
\text { after insertion }\end{array}$ & \\
\hline $\begin{array}{l}\text { Insulin should } \\
\text { preferably be at } \\
\text { room } \\
\text { temperature as } \\
\text { injection of } \\
\text { cold insulin is } \\
\text { painful }\end{array}$ & & \\
\hline
\end{tabular}

(5.6-7.2 $\mathrm{mmol} / \mathrm{L})$ and $\mathrm{HbA} 1 \mathrm{c} \leq 7.0 \%$ are reasonable goals for most adults. Once fasting control has been achieved, oral medication or prandial insulin may be needed to achieve postprandial control. Dietary modification and portion size control is non-negotiable and must be emphasized at all stages of intensification of therapy. Titration, in dose steps of 2-4 units, 


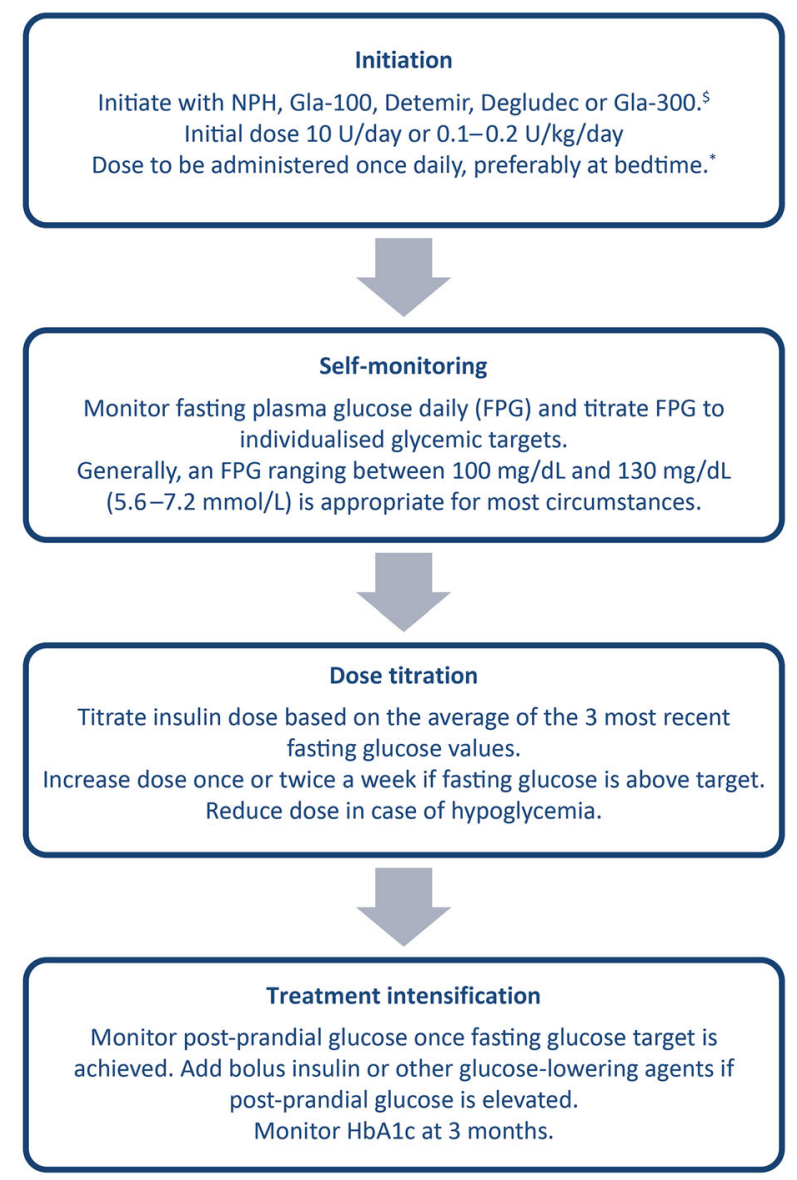

Fig. 1 Recommended treat-to-target algorithm for the initiation and titration of basal insulin in basal insulin supported oral antidiabetic therapy (BOT). ${ }^{\$}$ Basal insulin analogues such as glargine and detemir are associated with a lower risk of hypoglycemia and are preferred. Where cost is a constraint, neutral protamine Hagedorn $(\mathrm{NPH})$ can be used. In individuals at high risk of hypoglycemia, longeracting insulin analogues such as degludec or Gla-300 should be considered. "While once-daily basal insulin is preferably administered at bedtime, it can be administered any time of the day depending on the sociocultural circumstances. NPH and detemir may have to be administered twice a day in some individuals

should be initially performed once to twice a week until optimal control is achieved.

- Titration may be performed in steeper steps if the daily requirement is $>30 \mathrm{U} /$ day.

Physicians should refer to the prescribing information for the frequency of titration of a specific basal insulin.

- The recommended dose adjustments for insulin dose based on the mean or lowest
Table 3 Basal insulin dose adjustment [37]

\begin{tabular}{ll}
\hline $\begin{array}{l}\text { FPG (mg/dL) (mean of } \\
\text { the three most recent } \\
\text { values) }\end{array}$ & $\begin{array}{l}\text { Recommended dose } \\
\text { adjustment (once or twice } \\
\text { a week) }\end{array}$ \\
\hline $\begin{array}{l}<0 \mathrm{mg} / \mathrm{dL} \\
(<4.4 \mathrm{mmol} / \mathrm{L})\end{array}$ & Reduce dose by 2 units \\
$\begin{array}{l}80-130 \mathrm{mg} / \mathrm{dL} \\
(4.4-7.2 \mathrm{mmol} / \mathrm{L})\end{array}$ & No dose modification \\
$\begin{array}{r}131-160 \mathrm{mg} / \mathrm{dL} \\
(7.27-8.9 \mathrm{mmol} / \mathrm{L})\end{array}$ & Increase dose by 2 units \\
$\begin{array}{c}161-180 \mathrm{mg} / \mathrm{dL} \\
(8.94-10.0 \mathrm{mmol} / \mathrm{L})\end{array}$ & Increase dose by 4 units \\
$>180 \mathrm{mg} / \mathrm{dL}$ & Increase dose by 6 units \\
$(>10.0 \mathrm{mmol} / \mathrm{L})$ & \\
\hline
\end{tabular}

$F P G$ fasting plasma glucose

of the three most recent values of FPG are shown in Table 3 [37].

A simplified titration technique should be taught and demonstrated to the patient at the time of initiation of basal insulin. Patient-led titration regimens have been shown to be efficacious in achieving glycemic control.

- For instance, in the INSIGHT study, patientled titration using simple titration algorithms resulted in greater reductions in HbA1c than physician-led adjustment of oral antidiabetic drugs (control) $(-1.55 \%$ vs. $-1.25 \%, \quad-17$ vs. - $14 \mathrm{mmol} / \mathrm{mol}$, $P=0.005)$. The study also showed that compared to the control group, patients receiving Gla-100 were 1.68 times more likely to achieve two consecutive HbA1c levels $\leq 6.5 \%$, had lower FPG $(P=0.0001)$, nonhigh-density lipoprotein cholesterol $(P=0.02)$ and triglycerides $(P=0.02)$, and greater increases in treatment satisfaction $(P=0.045)$ [38].

- The AT.LANTUS trial compared an investigator-led insulin Gla-100 initiation and titration algorithm to that led by study subjects. It showed that there was a significant reduction in $\mathrm{HbA1c}$ (from $8.9 \pm 1.3 \%$ to $7.8 \pm 1.2 \%)$, with a greater decrease $(P<0.001)$ with the study subject-led 
algorithm $(-1.22 \%)$ than the investigatorled algorithm (-1.08\%) [39].

- The Asian Treat to Target Lantus Study (ATLAS) showed that self-titration with Gla100 was found to statistically significantly lower the mean HbA1c (by $1.40 \%$ for selftitration vs. $1.25 \%$ for physician-led titration) [40].

- The TAKE CONTROL study evaluated the self-titration and physician-led titration of Gla-300 in people with T2DM. Self-titration was found to statistically significantly lower the mean HbA1c (by $0.97 \%$ for self-titration vs. $0.84 \%$ for physician-led titration) [40]. Hence, self-titration with both Gla-100 and Gla-300 resulted in significantly improved glycemic control (vs. physician-led titration), without increased hypoglycemia [40]. Titration of the basal insulin dose may be done by the physician, diabetes care nurse, patient, or caregiver.

\section{Tablets}

Combination therapies (oral therapy combined with basal insulin or basal insulin combined with oral therapy) offer complementary mechanisms of action that can help maximize efficacy, reach target HbA1c goals, and minimize adverse events [41].

- Among the various GLAs, metformin is the preferred initial therapy (with HbA1c $\geq 6.5 \%$ and FPG level $\geq 126 \mathrm{mg} / \mathrm{dL}$ ). The advantages of including metformin are as follows [41, 42]:

- It is associated with less weight gain (useful in treating obese patients)

- Usage leads to decreased hepatic glucose production, blood pressure, and risk of atherothrombotic disease, thus reducing insulin requirements and blood levels of insulin

- Inclusion of metformin leads to increased hepatic sensitivity to insulin, and it may also have a mild effect on muscular sensitivity to insulin

- When adding sulfonylureas, start the therapy with low-dose sulfonylureas. The dosage can be increased at intervals of 2-4 weeks until the glycemic target is reached [43]. Modern sulfonylureas (glimepiride and gliclazide MR) confer a lower risk of hypoglycemia and are thus preferred over older sulfonylureas such as glibenclamide [44]. Clinical studies on the addition of sulfonylureas to basal insulin yielded the following results:

- Basal insulin + glimepiride: In a 24-week prospective randomized comparative study, basal insulin in addition to glimepiride offered better efficacy, less hypoglycemia, and less weight gain, and significantly reduced the insulin dose required (by $4.01 \%$ ) [45].

- Basal insulin + metformin + glimepiride: In a 28-week clinical trial, metformin and glimepiride plus insulin glargine resulted in a significant improvement in overall glycemic control as compared to other combinations. The decrease in HbA1c was more pronounced with insulin glargine plus glimepiride plus metformin than with insulin glargine plus metformin (0.49\% [CI, $0.16 \%-0.82 \%] ; P=0.005)$ $(5.10 \mathrm{mmol} / \mathrm{mol}$ [CI, $1.64-8.61] ; \quad P=$ $0.005)$ and insulin glargine plus glimepiride $(0.59 \% \quad[\mathrm{CI}, \quad 0.13 \%-1.05 \%] ; \quad P=$ 0.012) $(5.87 \mathrm{mmol} / \mathrm{mol}$ [CI, 1.10-10.64]; $P=0.012$ ) (overall $P=0.02$ ) [46].

- Regular monitoring is recommended, especially when combining with insulin secretagogues such as sulfonylureas.

- Thiazolidinediones, when combined with insulin, may favor weight gain and fluid retention [47].

- Pioglitazone or rosiglitazone helps reduce PPG levels [48].

- Alpha-glucosidase inhibitors (AGIs) should be considered as the first-line treatment in patients with controlled basal glucose concentrations and marked postprandial hyperglycemia. Mean HbA1c at week 24 was significantly decreased (by $0.7 \%$ from baseline) in both acarbose and voglibose patient groups who were previously inadequately controlled with basal insulin $[49,50]$.

- Sodium-glucose cotransporter 2 (SGLT2) inhibitors may be considered as add-ons to 


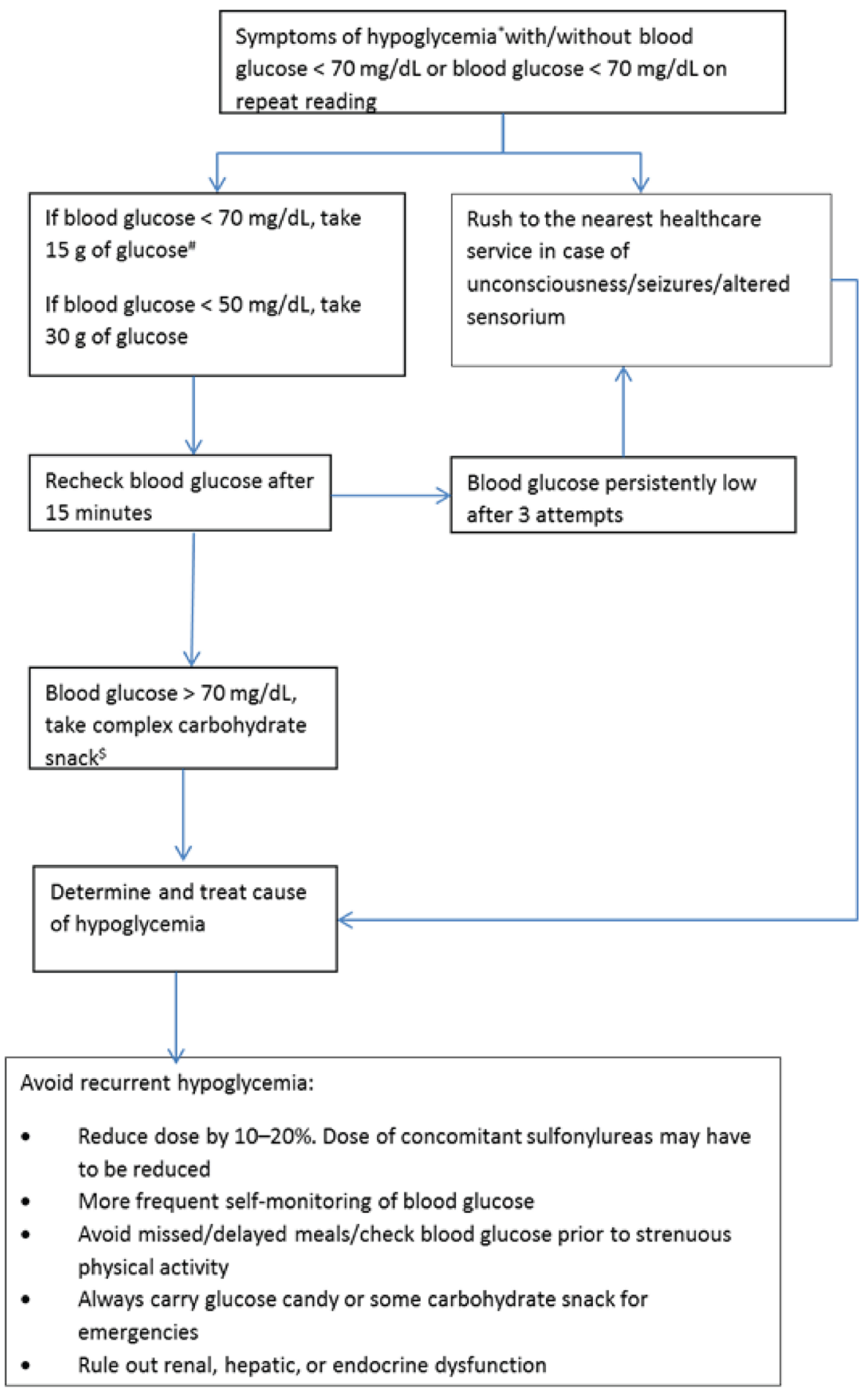

Fig. 2 Protocol for managing hypoglycemia. *Symptoms of hypoglycemia include excessive hunger, sweating, tremors, palpitations, irritability, blurring of vision, dizziness, difficulty concentrating, excessive tiredness, incoherent speech, and altered sensorium/seizures; symptoms of hypoglycemia are idiosyncratic. ${ }^{\#} 15 \mathrm{~g}$ of glucose or sucrose or $150 \mathrm{~mL}$ of fruit juice or sweetened beverages such as cola (not diet cola) can be administered. ${ }^{\text {\$Complex }}$ carbohydrate snack can include $150 \mathrm{~mL}$ milk, 1 bread sandwich, 1 chapati, or 3 heaped tablespoons of cooked rice. When hypoglycemia occurs prior to a meal, the meal should be taken immediately 
metformin alongside other drugs such as sulfonylureas, dipeptidyl peptidase 4 (DPP-4) inhibitors, thiazolidinedione, and basal insulin. SGLT2 inhibitors are associated with weight loss and do not increase the risk of hypoglycemia. They have potential benefits in terms of weight loss, reduction of blood pressure, improvements in glycemic control without weight gain, and hypoglycemic risks associated with insulin therapy [51].

- DPP-4 inhibitors are weight neutral and not associated with an increased risk of hypoglycemia. DPP-4 inhibitors lower PPG levels by decelerating gastric emptying. They best complement the action of basal insulin on fasting glucose control and help patients with T2DM achieve their target HbA1c [52].

- In general, GLP-1 receptor agonists (GLP1RAs) should not be discontinued with the initiation of basal insulin. Basal insulin and GLP-1RAs address various defects seen in T2DM physiopathology. Basal insulin plus GLP-1 receptor agonists are associated with less hypoglycemia and with weight loss instead of weight gain. However, they may be less tolerable and come at a greater cost. That said, a fixed ratio combination of GLP-1RA and basal insulin is a potentially helpful tool for the treatment of patients with T2DM as a result of its favorable safety and efficacy profile, especially in obese patients who are uncontrolled on OADs or basal insulin $[12,53]$.

\section{Tools for Monitoring and Troubleshooting}

- Second-generation basal insulin analogues (Gla-300 and degludec) are associated with the lowest risk of hypoglycemia, which can be further reduced by implementing timely therapy initiation, proper patient education, and SMBG. Hypoglycemia and need for monitoring is reduced with BOT as compared with basal bolus [24, 28].

- Regular SMBG is recommended in patients with diabetes on multiple daily insulin injections, with a history of hypoglycemia, and with poor metabolic control with multiple GLAs and/or basal insulin.
- SMBG should be performed at least as often as insulin is administered.

- The ideal SMBG requirement is seven tests/day, i.e., three before and three after each meal and one test at $3 \mathrm{am}$. As a compromise, one fasting test and three each after breakfast, lunch, and dinner daily may be more feasible as well as acceptable. This can be further individualized to twice or thrice a week in pregnant patients as the pregnancy advances. Two-hour post-meal monitoring may be easier to remember, as this timing is routinely used [4].

- For patients on intensive insulin regimens who are on multiple doses of insulin or on insulin pumps, testing should be carried out three or more times daily (all pre-meals, post-meals, at bedtime, and prior to exercise) [4].

- Some patients may require testing 6-10 (or more) times daily [4].

- Pregnant women with insulin-treated diabetes must be advised to perform SMBG on a daily basis. However, in case of any failure to do so, at least weekly monitoring should be encouraged [4].

- Meal-based testing schemes such as 5- and 7-point regimens and the staggered-frequency regimen can help to show the effect of food consumed on the rise in blood glucose after specific mealtimes [54].

- Monitoring hypoglycemia in patients: Severe hypoglycemia is a common acute complication in people with diabetes being treated with insulin, and its incidence increases with the duration of insulin therapy. A basal insulin switch from conventional to longacting or to ultra-long-acting preparations may be indicated if a particular insulin cannot be uptitrated due to hypoglycemia or glycemic variability.

Physicians can refer to the hypoglycemia protocol illustrated in Fig. 2.

- SMBG should be performed in a pragmatic manner. Once-daily FPG and structured 2-h PPG are acceptable SMBG strategies for BOT. Monitoring PPG levels will provide data on the adequacy of the BOT regimen [55].

- Tools for patients: Basal insulin titration and target achievement can be facilitated by the 
use of modern technology, including ambulatory glucose profiling and online apps. The Hypoglycemia Awareness Questionnaire can be used by patients to monitor glucose level changes and consult with their healthcare providers [56]. Several online apps are available in India, such as mySugr, OnTrack Diabetes, and MyFitnessPal, which patients can conveniently use to manage diabetes $[56,57]$.

- Risk factors for hypoglycemia can be reduced with the timely initiation of therapy using currently available insulin formulations and technologies (insulin pumps and monitoring) and proper patient education, which should empower physicians to overcome their inertia [24].

Summary of the 7-T concept of basal early strategies to maximize HbAlc reduction with oral therapy

Treatment initiation

Timing

Transportation and storage

Technique of administration

Targets for titration

Tablets
Begin basal insulin at $10 \mathrm{U} /$ day or $0.1-0.2 \mathrm{U} / \mathrm{kg} /$ day, depending on the degree of hyperglycemia

Basal insulin should be injected at the appropriate time (usually bedtime)

Under some circumstances, it may be administered at the same time daily, in the morning or afternoon

Insulin vials, cartridges, or pens may be kept at room temperature for 28 days to 1 month, depending on the type of insulin. However, in settings where the temperatures can be above $30{ }^{\circ} \mathrm{C}$ or below $2{ }^{\circ} \mathrm{C}$, it is not advisable to leave the vials at room temperature

The cold chain should be maintained during the transportation of the vials or cartridges of insulin Basal insulin, if injected into intramuscular space, may act like rapid-acting insulin

The abdomen is the preferred site for soluble human insulin as it leads to the fastest absorption

The initial basal insulin dose may be started at $10 \mathrm{U} /$ day or $0.1-0.2 \mathrm{U} / \mathrm{kg} / \mathrm{day}$, depending on the degree of hyperglycemia

Titration, in steps of 2-4 units, should be initially performed once to twice a week until optimal control is achieved

In combination with basal insulin:

- Metformin: Preferred initial therapy (with HbAlc $\geq 6.5 \%$ and FPG level $\geq 126 \mathrm{mg} / \mathrm{dL}$ )

- Sulfonylureas: Preferred agents where cost is a limiting factor. Begin at a low dose, but dosage can be increased at intervals of 2-4 weeks until the glycemic target is reached. Pioglitazone or rosiglitazone help reduce PPG levels

- AGIs: Used as the first-line treatment in patients with controlled basal glucose concentrations and marked postprandial hyperglycemia

- DPP-4 inhibitors: Weight neutral, not associated with an increased risk of hypoglycemia, and lowers PPG levels by decelerating gastric emptying, thus helping patients with T2DM achieve their target HbAlc levels

- SGLT2 inhibitors: Possess potential benefits in terms of renoprotection, cardiovascular risk reduction, weight loss, blood pressure reduction, and improvements in glycemic control without the weight gain and hypoglycemic risks associated with insulin therapy

- GLP-1 receptor agonists: Basal insulin plus GLP-1 receptor agonists are associated with less hypoglycemia and with weight loss instead of weight gain, but they may be less tolerable and cost more 
continued

Tools for

monitoring and troubleshooting
Once-daily FPG and strategic 2-h PPG are acceptable SMBG strategies for BOT
Hypoglycemia Awareness Questionnaire may be used by patients to monitor glucose level changes in consultation with their healthcare providers

Online apps, such as mySugr, OnTrack Diabetes, MyFitnessPal, and Diabeto, can be used by patients to manage diabetes and insulin dosing

\section{CONCLUSION}

The selection of an appropriate insulin regimen and initiation time as well as the optimization of insulin therapy are crucial to achieving optimal glycemic control. The strength of the current expert opinion statement is that it leverages clinical experience and regional expertise and practices to adapt existing recommendations on the basis of published evidence for local contexts.

We hope that these recommendations will prove useful to physicians as a reference. We envisage that these recommendations will highlight the need for the optimization and early intensification of basal insulin in the treatment of diabetes. The impact of these recommendations will be validated through observational studies in real-life diabetes outpatient practices.

\section{ACKNOWLEDGEMENTS}

We acknowledge the Sanofi India team-Dr. Shalini Menon, Dr. Senthilnathan Mohanasundaram, Dr. Romik Ghosh, and Dr. Amal Mathew-for their assistance, guidance, and expertise in convening the expert forum. The information contained herein solely represents the views and opinions of the authors. This expert opinion document does not seek to represent the opinions and policies of or the procedures used by Sanofi.
Funding. This expert opinion initiative was funded by Sanofi India. The article processing charges and the open access fee received by the journal for the publication of this article were sponsored by Sanofi India.

Medical Writing and/or Editorial Assistance. Editorial support was provided by Medulla Communications Private Limited, which was funded by Sanofi India.

Authorship. All named authors meet the International Committee of Medical Journal Editors (ICMJE) criteria for authorship for this manuscript, take responsibility for the integrity of the work, and gave final approval for the version to be published.

Disclosures. Jubbin Jacob received research funding for clinical trials from Novo Nordisk, Eli Lilly and Co., Sanofi Synthelabo Pvt. Ltd., and Biocon India Pvt. Ltd., and speaking assignments from Novo Nordisk India, Eli Lilly India Ltd., Sanofi Aventis India, Biocon, Lupin India, and AstraZeneca Pharma India Ltd. Deepak Khandelwal received a speaker honorarium from Sanofi. Manoj Chawla is on the advisory board for/has a speaker contract with/has a consultancy agreement with Sanofi India, Novo Nordisk India Pvt. Ltd., Eli Lilly India, Boehringer Ingelheim, MSD, AstraZeneca Pharma India Ltd., Novartis, Eris Lifesciences, and USV. Roberta Lamptey has served as consultant/speaker/advisory board member for Sanofi, Novo Nordisk, AstraZeneca and Novartis. Sarita Bajaj, AK Das, Rakesh Sahay, Banshi Saboo, Sambit Das, M. Shunmugavelu, 
Gagan Priya, Deep Dutta, Vineet Surana, Mangesh Tiwaskar, Ameya Joshi, Pradip Krishna Shrestha, Jyoti Bhattarai, Bishwajit Bhowmik, Tint Swe Latt, Than Than Aye, G. Vijayakumar, Manash Baruah, Fatema Jawad, A.G. Unnikrishnan, Subhankar Chowdhury, Md. Faruqe Pathan, Noel Somasundaram, Manilka Sumanathilaka, Abbas Raza, Silver K. Bahendeka, Ankia Coetzee, Sundeep Ruder, Kaushik Ramaiya, Charlotte Bavuma, Khalid Shaikh, Andrew Uloko, Sandeep Chaudhary, Abdurezak Ahmed Abdela, Zhanay Akanov, Joel Rodrìguez Saldaña, Raquel Faradji, Armindo Tiago, Ahmed Reja, and Leszek Czupryniak have nothing to declare. Sanjay Kalra is a member of the journal's Editorial Board.

Compliance with Ethics Guidelines. This article is based on previously conducted studies and does not involve any new study on human or animal subjects performed by any of the authors.

Open Access. This article is distributed under the terms of the Creative Commons Attribution-NonCommercial 4.0 International License (http://creativecommons.org/licenses/ by-nc/4.0/), which permits any noncommercial use, distribution, and reproduction in any medium, provided you give appropriate credit to the original author(s) and the source, provide a link to the Creative Commons license, and indicate if changes were made.

\section{REFERENCES}

1. Zheng Y, Ley SH, Hu FB. Global aetiology and epidemiology of type 2 diabetes mellitus and its complications. Nat Rev Endocrinol. 2018;14(2):88.

2. World Health Organization. Global report on diabetes. 2016. http://apps.who.int/iris/bitstream/ handle/10665/204871/9789241565257_eng.pdf;jse ssionid=6424E5BEBB8E 8DA1225A8A1462B1768A? sequence $=1$. Accessed 14 Jan 2018.

3. International Diabetes Federation. IDF diabetes atlas. 8th ed. 2017. https://www.idf.org/e-library/ epidemiology-research/diabetes-atlas.html. Accessed 15 Jan 2018.
4. Madhu SV, Saboo B, Makkar BM, et al. RSSDI clinical practice recommendations for management of type 2 diabetes mellitus, 2015. Int J Diabetes Dev Crit. 2015;35(1):1-71.

5. Kanungo S, Mahapatra T, Bhowmik K, et al. Diabetes scenario in a backward rural district population of India and need for restructuring of health care delivery services. Epidemiol. 2016;6(2):1.

6. Ray S, Pramanik S, Ghosh S. Combination treatment of oral agents and insulin in type 2 diabetes: a narrative review. Int J Diabetes Metab Disord. 2016;1(1):1-7.

7. ORIGIN Trial Investigators. Basal insulin and cardiovascular and other outcomes in dysglycemia. N Engl J Med. 2012;367(4):319-28.

8. American Diabetes Association. Implications of the United Kingdom Prospective Diabetes Study. Diabetes Care. 2002;25(Suppl 1):s28-32.

9. Lovre D, Fonseca V. Benefits of timely basal insulin control in patients with type 2 diabetes. J Diabetes Complications. 2015;29(2):295-301.

10. Mannucci E, Dicembrini I, Lauria A, Pozzilli P. Is glucose control important for prevention of cardiovascular disease in diabetes? Diabetes Care. 2013;36(Supplement 2):S259-63.

11. Al Mansari A, Obeid Y, Islam N, et al. GOAL study: clinical and non-clinical predictive factors for achieving glycemic control in people with type 2 diabetes in real clinical practice. BMJ Open Diabetes Res Care. 2018;6(1):e000519.

12. American Diabetes Association. Standards of medical care in diabetes-2018. http://care.diabetesjour nals.org/content/diacare/suppl/2017/12/08/41Supp lement_1.DC1/DC_41_S1_Combined.pdf. Accessed 15 Jan 2018.

13. American Diabetes Association. Standards of medical care in diabetes-2019 (abridged for primary care providers). Clin Diabetes. 2019;37(1):11.

14. Moses CA, Seshiah V, Sahay BK, et al. Baseline results indicate poor glycemic control and delay in initiation and optimization of insulin therapy: results from the Improving Management Practices and Clinical Outcomes in Type 2 Diabetes Study. Indian J Endocrinol Metab. 2012;16(Suppl 2):S432.

15. Khunti K, Davies MJ, Kalra S. Self-titration of insulin in the management of people with type 2 diabetes: a practical solution to improve management in primary care. Diabetes Obes Metab. 2013;15(8):690-700. 
16. Wangnoo SK, Maji D, Das AK, et al. Barriers and solutions to diabetes management: an Indian perspective. Indian J Endocrinol Metabol. 2013;17(4):594.

17. Russell-Jones D, Pouwer F, Khunti K. Identification of barriers to insulin therapy and approaches to overcoming them. Diabetes Obes Metab. 2018;20(3):488-96.

18. Unnikrishnan IR, Anjana RM, Mohan V. Importance of controlling diabetes early-the concept of metabolic memory, legacy effect and the case for early insulinisation. J Assoc Phys Indian. 2011;59(Suppl):8-12.

19. Avogaro A. Postprandial glucose: marker or risk factor? Diabetes Care. 2011;34:2333-5.

20. Peter R, Okoseime OE, Rees A, Owens DR. Postprandial glucose-a potential therapeutic target to reduce cardiovascular mortality. Curr Vasc Pharmacol. 2009;7(1):68-74.

21. Kalra S, Ved J, Baruah MP. Diabetes destiny in our hands: achieving metabolic karma. Indian J Endocr Metab. 2017;21(3):482.

22. Owens D. Clinical evidence for the earlier initiation of insulin therapy in type 2 diabetes. Diabetes Technol Ther. 2013;15(9):776-85.

23. Shrivastava SR, Shrivastava PS, Ramasamy J. Role of self-care in management of diabetes mellitus. J Diabetes Metab Disord. 2013;12(1):14.

24. Sorli C, Heile MK. Identifying and meeting the challenges of insulin therapy in type 2 diabetes. J Multidiscip Healthc. 2014;7:267.

25. Kalra S, Gupta Y, Unnikrishnan AG. Flexibility in insulin prescription. Indian $\mathrm{J}$ Endocr Metab. 2016;20(3):408.

26. Frid AH, Kreugel G, Grassi G, et al. New insulin delivery recommendations. Mayo Clin Proc. 2016;91(9):1231-55.

27. Standl E, Maxeiner S, Raptis S, Karimi-Anderesi Z, Schweitzer MA. Good glycemic control with flexibility in timing of basal insulin supply: a 24 -week comparison of insulin glargine given once daily in the morning or at bedtime in combination with morning glimepiride. Diabetes Care. 2005;28(2):419-20.

28. Mauricio D, Hramiak I. Second-generation insulin analogues-a review of recent real-world data and forthcoming head-to-head comparisons. Eur Endocrinol. 2018;14(Suppl1):2.
29. Meneghini L, Atkin SL, Gough SC, et al. NN12503668 (BEGIN FLEX) Trial Investigators. The efficacy and safety of insulin degludec given in variable once-daily dosing intervals compared with insulin glargine and insulin degludec dosed at the same time daily: a 26-week, randomized, open-label, parallel-group, treat-to-target trial in individuals with type 2 diabetes. Diabetes Care. 2013;36(4):858-64.

30. Ibrahim M, Al Magd MA, Annabi FA, et al. Recommendations for management of diabetes during Ramadan: update 2015. BMJ Open Diabetes Res Care. 2015;3(1):e000108.

31. Thomas N, Jeyaraman K, Asha HS, Velavan J. A practice guide to diabetes mellitus. 6th ed. New Delhi: Jaypee Brothers Medical Publishers Ltd.; 2012. https://books.google.co.in/books?id=FKnvtY 88WN8C\&pg=PA101\&lpg=PA101\&dq=transportati on + of + insulin +vials + in + India\&source=bl\&ots= 2VXj0933PT\&sig=NbRXRucNRn2St_ALhFDJtWlem Mc\&hl=en\&sa=X\&ved=0ahUKEwiROryMnpHZAhX Mpo 8KHfzQAGcQ6AEIbjAO\#v=onepage\&q=transp ortation\%20of\%20insulin\%20vials\%20in\%20India $\& \mathrm{f}=$ false. Accessed 7 Feb 2018.

32. Donner T. Insulin-pharmacology, therapeutic regimens and principles of intensive insulin therapy. Baltimore, MD: The Johns Hopkins University School of Medicine; 2015. https://www.ncbi.nlm. nih.gov/books/NBK278938/.

33. ADEA. Clinical guiding principles for subcutaneous injection technique. 2015. https://www.adea.com. au/wp-content/uploads/2015/11/Injection-Techniq ue-Final-digital-version2.pdf. Accessed 8 Feb 2018.

34. Bahendeka S, Kaushik R, Swai AB, et al. EADSG guidelines: insulin storage and optimisation of injection technique in diabetes management. Diabetes Ther. 2019:10(2):341-66.

35. Tandon N, Kalra S, Balhara YP, et al. Forum for injection technique and therapy expert recommendations, India: the Indian recommendations for best practice in insulin injection technique, 2017. Indian J Endocr Metab. 2017;21(4):600.

36. Garber AJ. Treat-to-target trials: uses, interpretation and review of concepts. Diabetes Obes Metab. 2014;16(3):193-205.

37. Shah S, Sharma SK, Singh P, et al. Consensus evidence-based guidelines for insulin initiation, optimization and continuation in type 2 diabetes mellitus. J Assoc Physicians India. 2014;62(7 Suppl):49-54.

38. Gerstein HC, Yale JF, Harris SB, et al. A randomized trial of adding insulin glargine vs. avoidance of insulin in people with type 2 diabetes on either no 
oral glucose-lowering agents or submaximal doses of metformin and/or sulphonylureas. The Canadian INSIGHT (Implementing New Strategies with Insulin Glargine for Hyperglycaemia Treatment) Study. Diabet Med. 2006;23(7):736-42.

39. Davies M, Storms F, Shutler S, Bianchi-Biscay M, Gomis R. Improvement of glycemic control in subjects with poorly controlled type 2 diabetes: comparison of two treatment algorithms using insulin glargine. Diabetes Care. 2005;28(6):1282-8.

40. Davies MJ, Boelle-Le Corfec EM, Bonnemaire M, et al. Self-titration with insulin glargine 300 or 100 $\mathrm{U} / \mathrm{mL}$ has improved efficacy vs. physician-led titration-comparison of the TAKE-CONTROL, AT. LANTUS, and ATLAS studies in people with type 2 diabetes (T2DM). Poster presented at ADA 2018. Diabetes. 2018;67(Suppl 1).

41. Kuritzky L. Addition of basal insulin to oral antidiabetic agents: a goal-directed approach to type 2 diabetes therapy. MedGenMed. 2006;8(4):34.

42. Wulffelé MG, Kooy A, Lehert P, et al. Combination of insulin and metformin in the treatment of type 2 diabetes. Diabetes Care. 2002;25(12):2133-40.

43. Sola D, Rossi L, Schianca GP, et al. Sulfonylureas and their use in clinical practice. Arch Med Sci. 2015;11(4):840.

44. Kalra S, Aamir AH, Raza A, et al. Place of sulfonylureas in the management of type 2 diabetes mellitus in South Asia: a expert opinion. Indian J Endocrinol Metab. 2015;19(5):577-96.

45. Kelwade J, Sethi B. Efficacy of glimepiride as an addon therapy to insulin in patients with high insulin requirement. Poster presented at IDF Congress 2017; 2017 Dec 4-8; Abu Dhabi, UAE.

46. Park CY, Kang JG, Chon S, et al. Comparison between the therapeutic effect of metformin, glimepiride and their combination as an add-on treatment to insulin glargine in uncontrolled patients with type 2 diabetes. PLoS One. 2014;9(3):e87799.

47. Charbonnel B, DeFronzo R, Davidson J, et al. Pioglitazone use in combination with insulin in the prospective pioglitazone clinical trial in macrovascular events study (PROactive19). J Clin Endocrinol Metab. 2010;95(5):2163-71.

48. Scheen AJ. Combined thiazolidinedione-insulin therapy. Drug Saf. 2004;27(12):841-56.

49. van de Laar FA. Alpha-glucosidase inhibitors in the early treatment of type 2 diabetes. Vasc Health Risk Manag. 2008;4(6):1189.

50. Lee MY, Choi DS, Lee MK, et al. Comparison of acarbose and voglibose in diabetes patients who are inadequately controlled with basal insulin treatment: randomized, parallel, open-label, activecontrolled study. J Korean Med Sci. 2014;29(1):90-7.

51. John M, Gopinath D, Jagesh R. Sodium-glucose cotransporter 2 inhibitors with insulin in type 2 diabetes: clinical perspectives. Indian J Endocrinol Metab. 2016;20(1):22.

52. Chen $\mathrm{C}, \mathrm{Yu} \mathrm{Q}$, Zhang S, et al. Assessing the efficacy and safety of combined DPP-4 inhibitor and insulin treatment in patients with type 2 diabetes: a metaanalysis. Int J Clin Exp Pathol. 2015;8(11):14141.

53. Moreira RO, Cobas R, Coelho RC. Combination of basal insulin and GLP-1 receptor agonist: is this the end of basal insulin alone in the treatment of type 2 diabetes? Diabetol Metab Syndr. 2018;10(1):26.

54. Austin MM. The two skill sets of self-monitoring of blood glucose education: the operational and the interpretive. Diabetes Spectr. 2013;26(2):83-90.

55. Kalra S, Khandelwal D. The Hypoglycaemia Awareness Questionnaire (HAQ). J Pak Med Assoc. 2018;68(2):322-3.

56. Woodfield J. Diabetes PA and the 10 best diabetes apps available. http://www.diabetes.co.uk/blog/ 2015/07/diabetes-pa-and-the-ten-best-diabetes-appsavailable/. Accessed 28 April 2018.

57. Doyle A. The Best diabetes apps of 2016. http:// www.healthline.com/health/diabetes/top-iphoneandroid-apps\#4. Accessed 28 April 2018. 